\title{
Mediação Tecnológica e Grupos de Integração como estratégias para o ensino remoto em tempos de pandemia da COVID-19 no IFPA - campus Paragominas
}

\author{
Technological Mediation and Integration Groups as an objective for remote teaching in times of \\ COVID-19 pandemic at IFPA - Paragominas campus \\ Mediación Tecnológica y Grupos de Integración como estrategias para la enseñanza remota en \\ tiempos de pandemia de COVID-19 en el IFPA - campus Paragominas
}

ORCID: https://orcid.org/0000-0002-5235-7146 Instituto Federal de Educação, Ciência e Tecnologia do Pará, Brasil E-mail: nubia.almeida@ifpa.edu.br

Jaqueline Pereira de Araújo

ORCID: https://orcid.org/0000-0003-0538-1490 Instituto Federal de Educação, Ciência e Tecnologia do Pará, Brasil E-mail: jaqueline.araujo@ifpa.edu.br Ieda Oliveira Mota

ORCID: https://orcid.org/0000-0001-9348-3774 Instituto Federal de Educação, Ciência e Tecnologia do Pará, Brasil E-mail: ieda.mota@ifpa.edu.br

Kátia Bárbara da Silva Santos

ORCID: https://orcid.org/0000-0003-1155-8205 Instituto Federal de Educação, Ciência e Tecnologia do Pará, Brasil E-mail: katia.santos@ifpa.edu

\begin{abstract}
Resumo
A suspensão das atividades presenciais nas instituições de ensino devido às restrições impostas pela COVID-19 provocou uma readequação do sistema educacional brasileiro. Diante desse cenário, este trabalho apresenta as estratégias adotadas pelo Instituto Federal do Pará - campus Paragominas para a implementação do ensino remoto emergencial. O estudo expõe as ferramentas tecnológicas usadas para as interações síncronas e assíncronas e a criação dos grupos de integração por componentes curriculares para a atuação no ensino e/ou organização de material didático. Ademais, descreve um relato de experiência com aulas integradoras entre as disciplinas de Educação Física e Sociologia. Nesse contexto, o campus Paragominas reconfigurou a metodologia tradicional de ensino com o uso das mídias digitais associadas às ações didático-pedagógicas integradas dando continuidade às atividades letivas do ano de 2020.
\end{abstract}

Palavras-chave: Ensino remoto; Tecnologias digitais; Grupos de integração.

\begin{abstract}
The suspension of in-person activities in educational institutions, due to the restrictions imposed by COVID-19, it caused a readjustment of the Brazilian educational system. Given this scenario, this work presents the strategies adopted by the Federal Institute of Pará - Paragominas campus for the implementation of emergency remote learning. The study exposes the technological tools used for synchronous and asynchronous interactions and the creation of integration groups by curricular components to work in teaching and/or organizing teaching materials. Furthermore, it describes an experience report with integrating classes between the disciplines of Physical Education and Sociology. In this context, the Paragominas campus reconfigured the traditional teaching methodology with the use of digital media associated with integrated didactic-pedagogical actions, continuing the teaching activities of the year 2020 .
\end{abstract}

Keywords: Remote teaching; Digital Technologies; Integration groups.

\section{Resumen}

La suspensión de las actividades presenciales en las instituciones de enseñanza debido a las restricciones impuestas por la COVID-19 provocó una readecuación del sistema educativo brasileño. Ante ese escenario, este trabajo presenta las estrategias adoptadas por el Instituto Federal de Pará - campus Paragominas para la implementación de la 
enseñanza remota de emergencia. El estudio expone las herramientas tecnológicas utilizadas para las interacciones síncronas y asíncronas y la creación de los grupos de integración por componentes curriculares para la actuación en la enseñanza y/u organización de material didáctico. Además, describe un relato de experiencia con clases integradoras entre las disciplinas de Educación Física y Sociología. En ese contexto, el campus Paragominas reconfiguró la metodología tradicional de enseñanza con el uso de los medios digitales asociados a las acciones didácticopedagógicas integradas dando continuidad a las actividades lectivas del año 2020.

Palabras clave: Enseñanza remota; Tecnologías digitales; Grupos de integración.

\section{Introduçãa}

A pandemia causada pela COVID-19 provocou mudanças significativas no sistema educacional. Segundo a Organização das Nações Unidas para a Educação, a Ciência e a Cultura mais de $70 \%$ dos estudantes em todo o mundo foram impactados com a suspensão das aulas presenciais, em virtude do distanciamento social necessário para o controle e diminuição à propagação do coronavírus (UNESCO, 2020).

Diante desse cenário e buscando a continuidade das atividades letivas, o Ministério de Educação do Brasil através da Portaria $\mathrm{N}^{\circ}$ 544, de 16 de junho de 2020, autorizou às instituições de ensino a modalidade não presencial utilizando tecnologias de informação e de comunicação (TICs) (Brasil, 2020a). Esse órgão por meio do Parecer $N^{\circ}$ 5/2020 evidenciou o desenvolvimento das propostas pedagógicas emergenciais por videoaulas, em ambientes virtuais de ensino, redes sociais, correio eletrônicos, transmissão por TV e rádio, e/ou distribuição de material didático impresso. Ademais, destacou que a organização de ensino, independente da estratégia empregada, deve alcançar as metas de aprendizagem previstas em cada componente curricular, assegurar a qualidade de ensino, cumprir a carga horária mínima prevista na Lei de Diretrizes e Bases da Educação Nacional, manter a interação com os alunos, observar a realidade e os limites de acesso dos estabelecimentos de ensino e dos discentes às diversas tecnologias, considerando propostas inclusivas, e, evitar o aumento de reprovações (Brasil, 2020b).

Segundo Behar (2020) a modalidade de ensino que pressupõe o distanciamento geográfico e que foi adotada nos diferentes níveis do sistema educacional brasileiro, na conjuntura pandêmica, vem sendo chamado de Ensino Remoto Emergencial (ERE). A autora destaca que o ERE é um regime temporário em que as atividades escolares são executadas principalmente em plataformas virtuais com encontros síncronos e assíncronos. Moran (2015) apud Barbosa e Almeida (2020) informa que nesse formato de ensino as estratégias de interação precisam ser atrativas podendo utilizar atividades integradas entre disciplinas e ferramentas lúdicas. Assim, ações motivadoras são fundamentais para o envolvimento dos discentes nas atividades escolares, conforme apresentado no trabalho de Paz et al., (2021).

Valente et al., (2020) apontam alguns desafios enfrentados pelo ERE tais como, a falta de acessibilidade digital por parte dos alunos e a necessidade de capacitação docente para efetivação dessa prática. De acordo com esses autores, as instituições de ensino vêm tentando contornar essas questões através do empréstimo de equipamentos e da oferta de bolsas aos estudantes com vulnerabilidade para compras de pacotes de dados, e, também pelo regimento institucional com resoluções que orientam as ações dos gestores e dos docentes.

Considerando a situação descrita, o Instituto Federal do Pará (IFPA) campus Paragominas que oferece uma educação gratuita e de excelência aos 619 alunos, matriculados em 2020, distribuídos nos cursos Técnicos em Informática Integrado ao Ensino Médio (IEM), em Meio Ambiente IEM, em Redes de Computadores IEM na modalidade de Educação de Jovens e Adultos (EJA), em Administração Subsequente ao Ensino Médio (SEM), em Redes de Computadores SEM, em Instrumento Musical SEM, e, Pós-graduação em Educação do Campo, aderiu ao Ensino Remoto Emergencial para o ano letivo de 2020.

Nessa conjectura, cabe a todos os envolvidos no processo educacional unir esforços para refletir sobre as propostas mais adequadas às diversas realidades visando pelo menos atenuar os impactos da COVID-19. Com base nisto, este artigo tem 
como objetivo apresentar as estratégias remotas adotadas pelo IFPA - campus Paragominas através da mediação tecnológica e de grupos integradores das disciplinas curriculares no período letivo de 2020.

\section{Metodologia}

A pesquisa é um estudo de caso descritivo do tipo relato de experiência de natureza qualitativa que aborda as estratégias pedagógicas adotadas pelo Instituto Federal do Pará (IFPA) campus Paragominas no ano letivo de 2020, para uma reconfiguração do processo de ensino e aprendizagem. O objetivo é descrever a experiência dos grupos de integração por meio da mediação tecnológica como estratégia para desenvolvimento do ensino remoto no ano de 2020. Conforme Pereira, et al., (2018) essa pesquisa é interessante por apresentar fenômenos com características diferenciadas do dia a dia de sala. A mediação tecnológica e os grupos de integração são realidades pouco vivenciadas nas escolas brasileiras, e, em tempos de pandemia, tornou-se um desafio ainda maior, portanto, trata-se de uma particularidade que merece ser descrita e analisada (PEREIRA, et al., 2018).

Inicialmente reuniões virtuais com os colegiados dos cursos foram realizadas pela Direção de Ensino do campus para discutir e viabilizar as propostas de retorno às atividades escolares na modalidade remota. O campus foi respaldado pelo Conselho Superior (CONSUP) através da Resolução $\mathrm{N}^{\circ} 110$, de 20 de julho de 2020, que aprovou o Regulamento de Atividades de Ensino não presencial. Nessa conjuntura, destacaram-se as mediações didáticas explorando as tecnologias de informação e de comunicação (TICs) e a criação dos grupos de integração (GIs) pelos coordenadores dos cursos auxiliados pelo replanejamento dos componentes curriculares. Os GIs trabalharam com a integração entre as disciplinas e/ou sob os aspectos de organização estrutural do material didático disponibilizado para os alunos. A Tabela 1 apresenta o modelo de organização dos grupos de integração por componentes curriculares para o ensino médio.

Tabela 1 - Modelo de organização dos grupos de integração por componentes curriculares.

\begin{tabular}{c|c}
\hline Identificação dos Grupos de Integração & Componentes Curriculares \\
\hline $\mathrm{GI}_{1}$ & $\begin{array}{c}\text { Língua Portuguesa e Literatura, Redação, Artes, } \\
\text { Inglês, Espanhol. }\end{array}$ \\
\hline $\mathrm{GI}_{2}$ & $\begin{array}{c}\text { História, Geografia, Educação Física, Filosofia e } \\
\text { Sociologia. }\end{array}$ \\
\hline $\mathrm{GI}_{3}$ & $\begin{array}{c}\text { Física, Química, Química Ambiental, Biologia, } \\
\text { Estatística, Matemática. }\end{array}$ \\
\hline $\mathrm{GI}_{4}$ & Específicas I $(*)$ \\
\hline $\mathrm{GI}_{5}$ & Específicas II $(*)$ \\
\hline
\end{tabular}

(*): Refere-se às disciplinas da base técnica dos cursos oferecidos pelo campus Paragominas.

Fonte: Autores (2021).

Após a reestruturação das propostas didático-pedagógicas, foi realizada uma reunião com os professores onde foi delineado o cronograma anual de acordo com os GIs. A seleção das TICs a serem empregadas ficou a critério do planejamento de cada docente. Ao término do ano letivo de 2020 foi encaminhado para os docentes um questionário elaborado no Google Forms para o levantamento das principais ferramentas tecnológicas utilizadas no ensino remoto no campus Paragominas.

Neste trabalho também será descrito um relato de experiência com ação integradora entre as disciplinas de Educação Física e Sociologia para as turmas dos $2^{\circ}$ e $3^{\circ}$ anos do Ensino Médio do campus. 


\section{Resultados e Discussão}

A suspensão das atividades escolares presenciais, consequência da pandemia da COVID-19, levou às instituições de ensino a modalidade remota utilizando tecnologias de informação e de comunicação (TICs) como meios que permitissem a manutenção e continuidade dos processos educativos (Brasil, 2020a.; Almeida e Barbosa, 2020; Almeida, et al., 2021). O uso das TICs faz parte das competências gerais da Educação Básica presentes na Base Nacional Comum Curricular (BNCC) que deve ser desenvolvida de forma crítica, reflexiva e ética nas diversas práticas sociais, incluindo as escolares (BNCC, 2020). Nesse contexto, o ensino remoto emergencial trouxe reformulações pedagógicas e uma nova rotina aos docentes e alunos, onde a casa passou a ser a sala de aula.

No Instituto Federal do Pará (IFPA), campus Paragominas, as TICs não eram tão exploradas como recursos didáticos no ensino presencial. No entanto, no decorrer do ano de 2020 as tecnologias digitais tornaram-se protagonistas na organização das práticas educativas, sendo para o atual contexto uma das principais referências para a educação contemporânea. Nessa modalidade de ensino, os docentes do campus ministraram os conteúdos curriculares em plataformas ou aplicativos diversos, com atividades síncronas e assíncronas, dinamizando os ambientes virtuais em cada encontro. A Figura 1 apresenta as principais ferramentas virtuais empregadas pelos docentes do campus no ano letivo de 2020.

Figura 1 - Ferramentas digitais utilizadas pelos docentes do campus Paragominas nas atividades de ensino remoto.

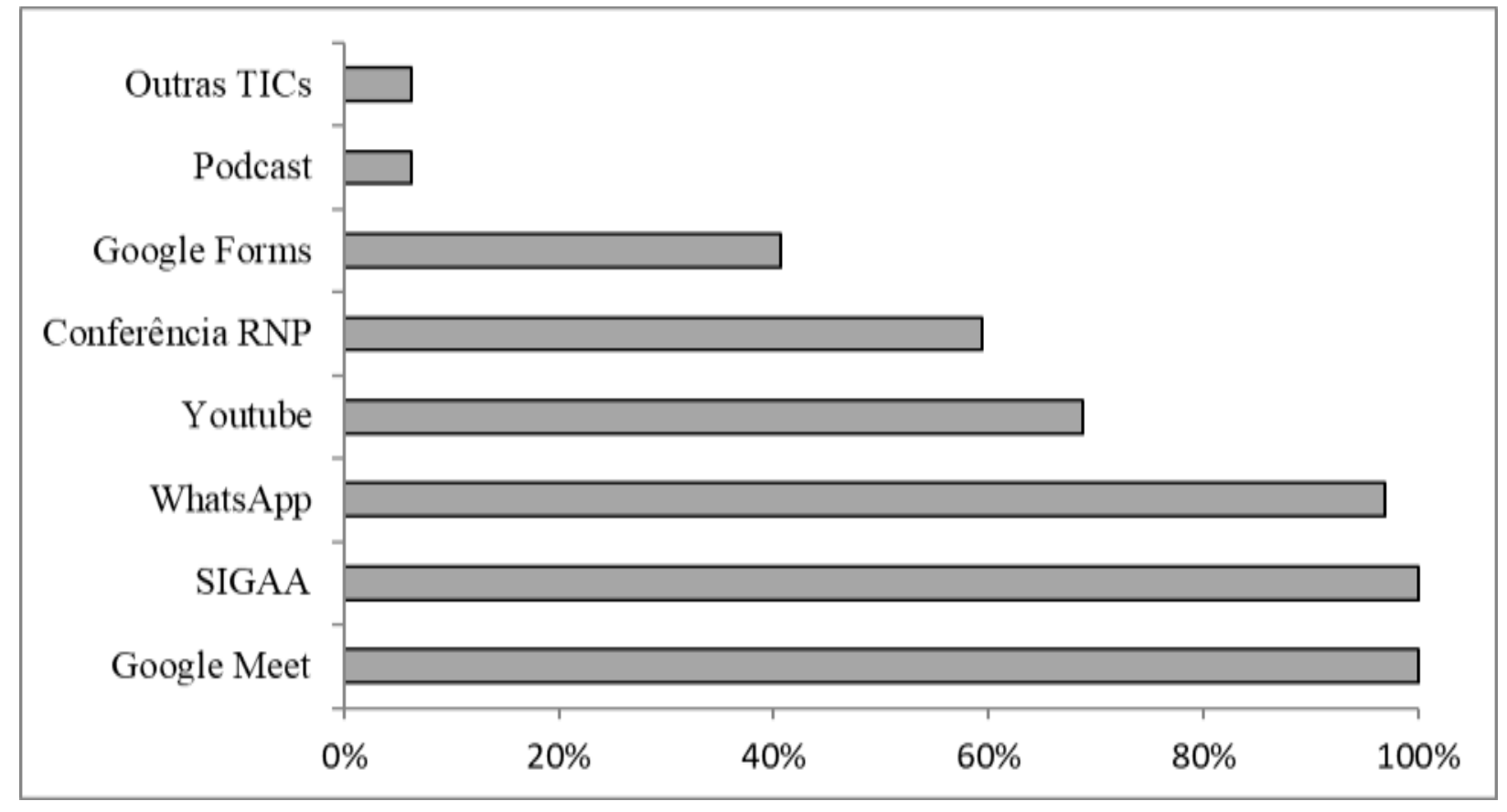

Fonte: Autores (2021).

De acordo com a Figura 1, entre as plataformas de streaming Google Meet, youtube, conferência WEB da RNP e Podcast, a primeira foi a mais utilizada por ser a ferramenta que mais se adequou as configurações dos celulares dos alunos, permitindo as interações remotas. Aproximadamente $70 \%$ dos docentes destacaram o uso do youtube como artifício tecnológico para transmissão do conhecimento. O ambiente virtual RNP ocupou a terceira posição como o serviço de comunicação interativa empregada por $60 \%$ dos professores. Já o uso de Podcast teve uma pequena adesão em relação aos demais recursos supramencionados. Isso pode estar relacionado à popularização mais recente dessa tecnologia. Os resultados obtidos também mostraram a importância da rede de comunicação instantânea, WhatsApp, especialmente para informes destacados por $97 \%$ da população amostral e da plataforma oficial do IFPA, o Sistema Integrado de Gestão de Atividades 
Acadêmicas (SIGAA) para disponibilização de material de estudo e avaliativo de forma unânime pelos docentes. Ademais, $41 \%$ dos professores usaram o aplicativo de gerenciamento o Google Forms para as atividades escolares. Em relação às outras TICs, com um uso de apenas 2\%, foram mencionados o Google Classroom, Stream Yard, Canva, Mindmeter, Jamboard, Padlet, Dashmyclass e Open Broadcaster Software (OBS).

Diante da situação pandêmica, o emprego dessas tecnologias causou uma tensão educacional, pois muitos docentes tiveram que aprender a utilizar esses recursos de uma maneira rápida e eficiente. Os alunos também encontraram dificuldades, como a falta de acesso a um dispositivo para assistir às aulas remotas, problemas de conexão com a internet e a desmotivação. Isso corrobora com os estudos de Silva et al., (2020) em relação aos desafios enfrentados pelos professores e estudantes nessa modalidade de ensino, que abrangem desde de questões de aptidão com os recursos tecnológicos até problemas emocionais.

Vieira e Souza (2015) alertam que o êxito na modernização tecnológica na educação só será alcançado se todos tiverem acesso às mídias digitais e se os princípios pedagógicos forem coerentes com a realidade educacional de cada contexto. Diante disso, o IFPA por meio da Resolução $\mathrm{N}^{\circ}$ 85, de 28 de abril de 2020, aprovou a concessão de auxílio de inclusão digital para os alunos que comprovaram situação de vulnerabilidade social. Além disso, esses discentes foram contemplados com chip/pacotes de dados de internet e aquisição de equipamentos de informática através dos Editais: No 07/2020 (Projeto Alunos Conectados MEC/RNP) e No 08/2020 (Auxilio de Inclusão Digital). Com essas políticas o campus de Paragominas possibilitou o acesso desses estudantes às atividades remotas atendendo com equidade e justiça, que segundo Ribeiro et al., (2019) orientam o bem social altamente valorizado na sociedade contemporânea: o conhecimento.

Com a exitosa utilização das TICs e a necessidade de aprimorar as metodologias visando um coeficiente expressivo do processo de aprendizagem significativa, a comunidade acadêmica do campus Paragominas foi conduzida à reflexão: "De que forma poderíamos usar o Ensino Remoto Emergencial (ERE) em um trabalho integrado visando à interdisciplinaridade?". Baseado nesta perspectiva, os docentes do campus que atuam no Ensino Médio utilizaram a integração entre os componentes curriculares usando as TICs e/ou organização estrutural de material didático.

Em relação ao processo de integração, observa-se um desafio aos docentes, uma vez que as exigências do sistema educacional, pautadas na lógica tradicionalista, direcionam a ação pedagógica para um determinado tipo de conhecimento que não dialoga com as diferentes áreas que compõe o currículo escolar (Pinho et al.; 2018). Essas imposições, associadas às limitações no processo de formação dos professores, fortalecem práticas com enfoque nos conteúdos, ainda predominantes nas escolas (Magalhães Jr.; Cavaignac, 2018). De acordo com Fazenda (2010) a integração de áreas curriculares pode ser compreendida como uma interação de conhecimentos com afinidades entre si, expressas pela referência de um ponto em comum, configurando um aspecto formal da interdisciplinaridade. Para esta autora, isto não significa extinguir a especificidade e objetividade de cada disciplina, uma vez que a interação ativa entre os diversos saberes permite a construção do conhecimento significativo. Isto nos possibilita compreender Morin (2005 p.136) ao afirmar que "a ciência nunca teria sido ciência se não tivesse sido transdisciplinar".

Sobre o aspecto organizacional, cada Grupo de Integração (GI) sistematizou os conteúdos curriculares em materiais didáticos, objetivos e dinâmicos, tendo como interação docente o WhatsApp. O acesso destes foram através da plataforma oficial SIGAA que algumas vezes dificultou a conexão do aluno pela instabilidade do sistema. No geral, todos os GIs atuaram no planejamento coletivo para o cronograma de aulas síncronas, compilação de material de apoio didático e acompanhamento discente. Isso permitiu a aceitação da estratégia de ensino remoto e manteve o vínculo com os alunos buscando o processo de aprendizagem significativa. Para Lima et al., (2020) essa aprendizagem favorece o desenvolvimento das competências socioemocionais como a empatia, confiança, autoestima, ética, paciência, autoconhecimento, responsabilidade, autonomia e criatividade. 
Em relação às aulas integradas destaca-se neste estudo a experiência entre as disciplinas de Educação Física e Sociologia aplicada com as turmas do $2^{\circ}$ e $3^{\circ}$ anos do Ensino Médio. As figuras 1 e 2 mostram o fluxograma do planejamento dessas aulas.

Figura 1 - Fluxograma delineado para o desenvolvimento da aula integradora entre as disciplinas de Educação Física (assunto: nutrientes) e Sociologia (assunto: desigualdade social) para as turmas dos $2^{\circ}$ anos.

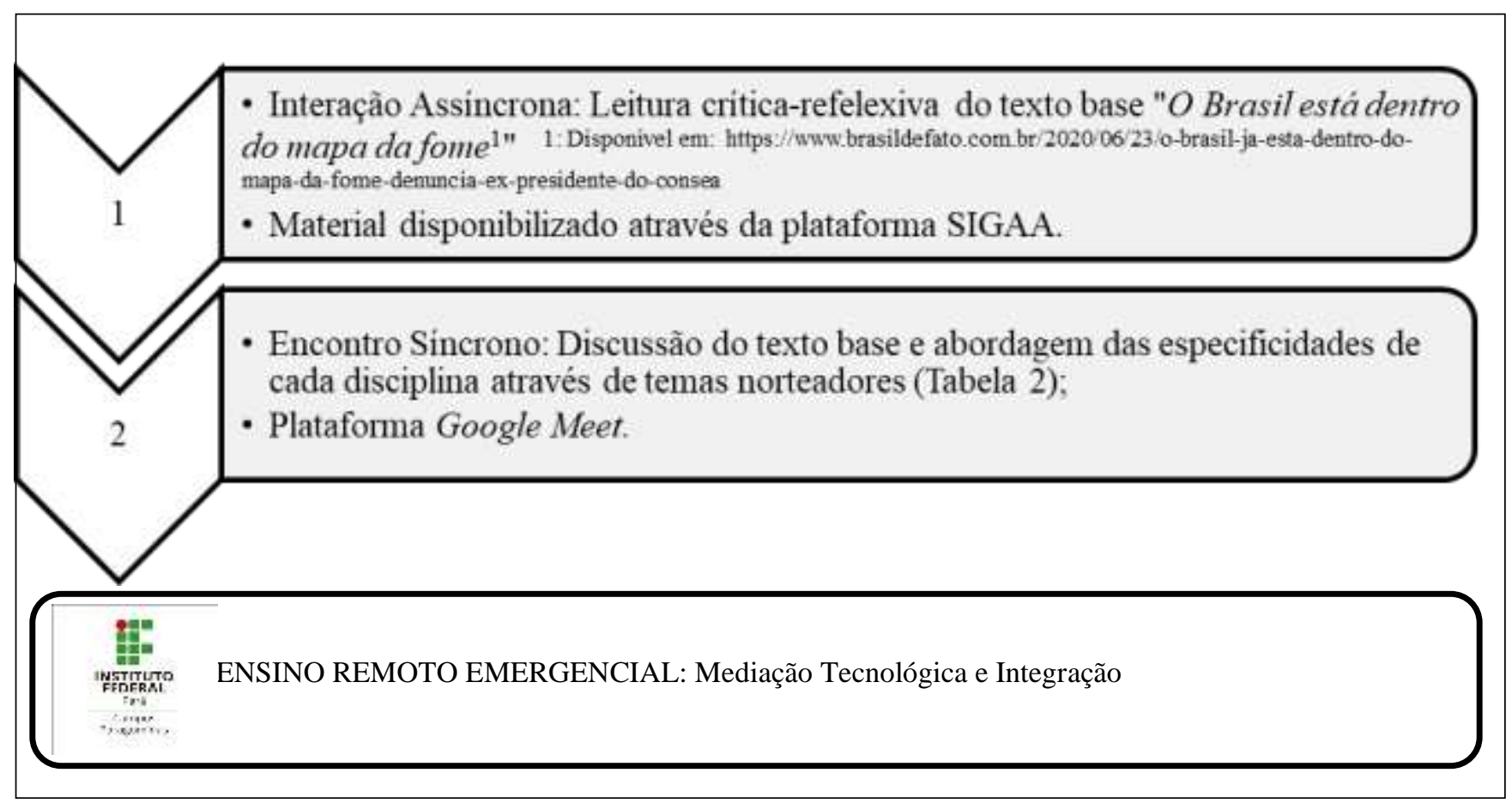

Fonte: Autores (2021). 
Figura 2 - Fluxograma delineado para o desenvolvimento da aula integradora entre as disciplinas de Educação Física (assunto: corpo) e Sociologia (assunto: globalização) para as turmas dos $3^{\circ}$ anos.

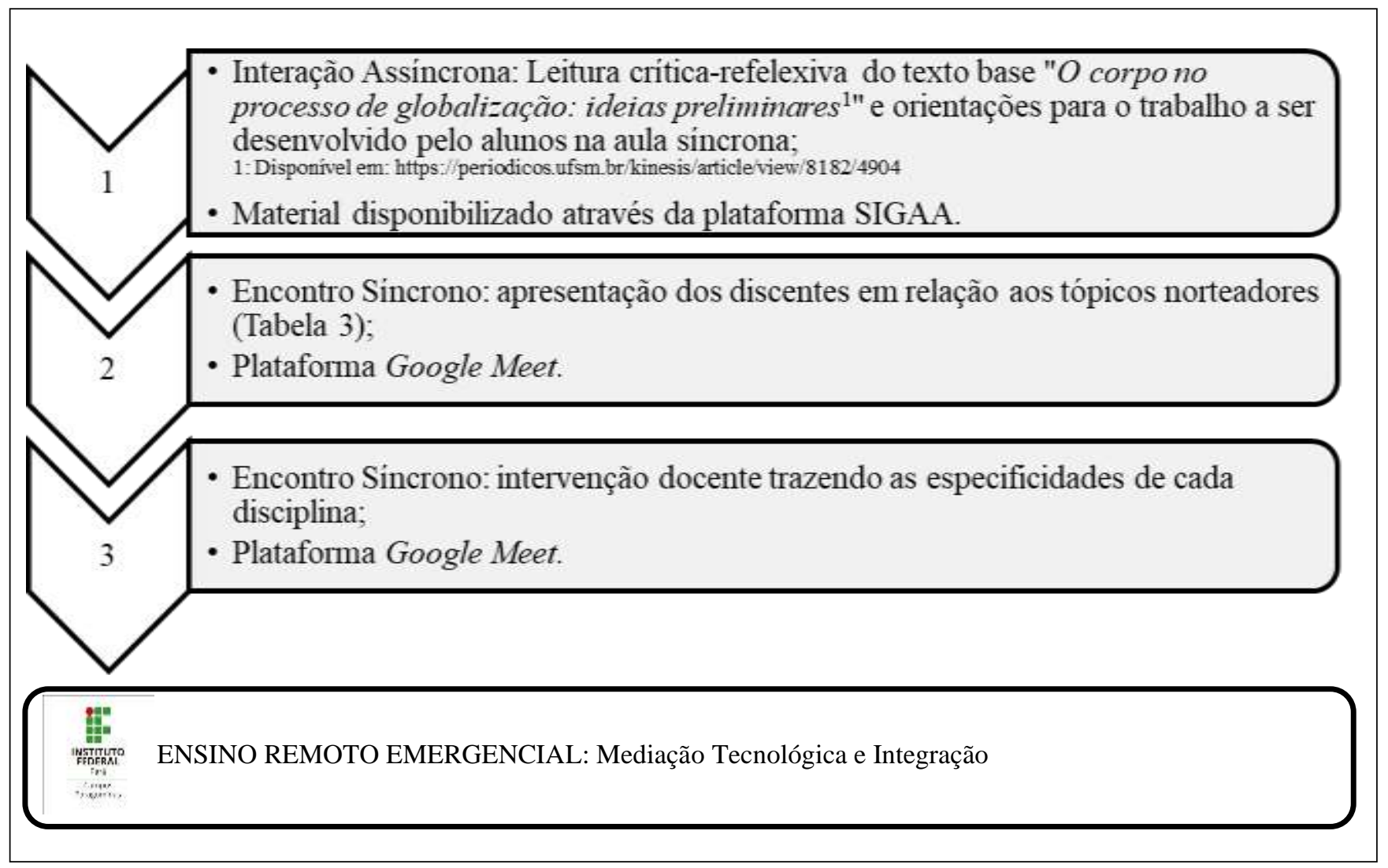

Fonte: Autores (2021).

A seguir as Tabelas 2 e 3 referem-se aos eixos norteadores para as aulas de integração das turmas nos $2^{\circ}$ e $3^{\circ}$ anos respectivamente.

Tabela 2 - Tópicos norteadores de integração entre as disciplinas de Educação Física e Sociologia para as turmas dos $2^{\circ}$ anos.

\begin{tabular}{l|l}
\hline 1 & Isolamento social e a influência na fonte de renda dos trabalhadores. \\
\hline 2 & A alimentação: fonte de energia para o funcionamento do corpo e a escassez com a pandemia. \\
\hline 3 & $\begin{array}{l}\text { A dupla: feijão com arroz, combinada com uma proteína substituída pelos alimentos com baixo potencial nutritivo, } \\
\text { como os enlatados. }\end{array}$ \\
\hline 4 & $\begin{array}{l}\text { Carência de nutrientes e as implicações no desenvolvimento infantil, a alimentação e a relação com a imunidade e o } \\
\text { desenvolvimento físico e mental. }\end{array}$ \\
\hline
\end{tabular}

Fonte: Autores (2021). 
Tabela 3 - Questões norteadoras de integração entre as disciplinas de Educação Física e Sociologia para as turmas dos $3^{\circ}$ anos.

\begin{tabular}{c|l}
\hline 1 & $\begin{array}{l}\text { Crie argumentos que justifiquem as formas que a Globalização atinge as diversas esferas da vida: padrões de trabalho, } \\
\text { lazer, educação, expressões artísticas e tecnologias. }\end{array}$ \\
\hline 2 & Como a globalização influencia a cultura corporal? \\
\hline 3 & Analise a seguinte frase "o corpo é expressão da cultura" e cada cultura é expressa por “diferentes corpos”. \\
\hline 4 & $\begin{array}{l}\text { A globalização permite o acesso a recursos que auxiliam na construção do padrão ideal de beleza estética. Como esses } \\
\text { recursos influenciam na construção de um padrão de beleza hegemônico? }\end{array}$ \\
\hline 5 & $\begin{array}{l}\text { No texto, é possível identificar a ideia de que o corpo é uma mercadoria. Como a globalização contribui para a } \\
\text { indústria corporal? }\end{array}$ \\
\hline 6 & No texto base se cogita a existência de dois corpos "o corpo que se vê e o coro que se sente”. Justifique. \\
\hline
\end{tabular}

Fonte: Autores (2021).

As aulas integradas entre as disciplinas de Educação Física e Sociologia, através da plataforma Google Meet, permitiram um momento síncrono dinâmico o que culminou em uma maior interação entre os alunos e professores A ação didática voltada para a interdisciplinaridade com mediação tecnológica também proporcionou uma reflexão crítica e contextualizada dos assuntos abordados e favoreceu a autonomia e o diálogo. Segundo Pimentel e Carvalho (2020) e Piffero et al., (2020) esse tipo abordagem pedagógico aponta para o desenvolvimento de uma escola participativa e reconfigurada, onde os espaços virtuais se caracterizam como locais de produção de conhecimento.

Os eixos norteadores (Tabelas 2 e 3) facilitaram a condução da integração nas turmas do $2^{\circ}$ e $3^{\circ}$ anos e potencializaram a compreensão dos estudantes em relação aos temas. Isto foi observado principalmente nas turmas do $3^{\circ}$ anos em que a estratégia utilizada requereu dos alunos a apresentação das questões da Tabela 3. Com essa estratégia de ensino, os estudantes passaram a ser protagonistas do processo de aprendizagem desempenhando uma função coparticipativa na criação e desenvolvimento da aula integrada. A postura pedagógica foi centrada no crescimento cognitivo e social dos educandos sendo os docentes um mediador entre os alunos e o conhecimento. Alguns desafios se impuseram na ação integradora com os $3^{\circ}$ anos, como a organização dos grupos de trabalhos e o acesso à internet de qualidade que garantisse as apresentações dos estudantes. Porém, cabe ressaltar que a eficácia de uma aprendizagem significativa na perspectiva educacional remota depende de um acesso igualitário, qualidade da internet, estrutura tecnológica, formação e capacitação do docente (Joye, et al., 2020).

\section{Considerações Finais}

Pode-se inferir que as estratégias pedagógicas adotadas pelo IFPA campus Paragominas, para continuidade do ensino na modalidade remota foram alternativas efetivas que mantiveram uma rotina escolar durante a situação pandêmica no ano letivo de 2020. As ações tiveram adesão significativa dos docentes nas aulas empregando os recursos tecnológicos pelo uso das TICs e explorando a interdisciplinaridade na construção de materiais didáticos através dos grupos de integração por componentes curriculares.

As propostas didáticas foram desafiadoras, tanto para os estudantes quanto para os docentes, uma vez que todos tiveram que aprender a utilizar esses recursos tecnológicos para fins de estudos de uma maneira rápida e eficiente, além de enfrentar dificuldades relacionadas à instabilidade e o acesso à internet. Contudo, identificou-se ao final do ano letivo a apropriação, integração e envolvimento da comunidade escolar nas ações executadas.

As aulas de integração entre as disciplinas de Educação Física e Sociologia trouxeram um ambiente virtual dinâmico que proporcionou uma efetiva participação dos discentes culminando na potencialização da aprendizagem em relação aos conteúdos apresentados. A mediação docente pautou-se em uma contextualização social, política, econômica e cultural. 


\section{Agradecimentos}

Ao Grupo de Pesquisa: Multidisciplinar em Ensino, Educação, Química, Linguagens e Meio Ambiente - IFPA Campus Paragominas pelo incentivo à pesquisa.

\section{Referências}

Almeida, D. V. de. \& Barbosa, S. D. P. (2020). O ensino remoto emergencial: mediação tecnológica e estratégias de ensino-aprendizagem. Caderno Intersaberes. 9(22). file:///C:/Users/andre/Downloads/1585-Texto\%20do\%20artigo-4365-1-10-20210202\%20(2).pdf

Almeida, N. R. de, Sousa, R. C. de, Santos, J. C. dos \& Franco, I. dos S. B. (2021). A importância do uso de ferramenta digital para acompanhamento sistemático do processo ensino-aprendizagem em tempos de pandemia. Revista Educação Pública, 21(24). https://educacaopublica.cecierj.edu.br/artigos/21/24/a-importancia-do-uso-de-ferramenta-digital-para-acompanhamento-sistematico-do-processo-ensinoaprendizagem-em-tempos-de-pandemia

Behar, P. A. (2020). O Ensino Remoto Emergencial e a Educação a Distância. UFRGS.

Brasil. (2021). BNCC - Base Nacional Comum Curricular. Plano Nacional de Educação (PNE), Ministério da Educação. http://basenacionalcomum.mec.gov.br/

Brasil. (2020a). Ministério da Educação. Portaria $\mathrm{N}^{\circ}$ 544, de 16 de junho DE 2020. Dispõe sobre a substituição das aulas presenciais por aulas em meios digitais, enquanto durar a situação de pandemia do novo coronavírus - Covid-19, e revoga as Portarias MEC $\mathrm{n}^{\circ} 343$, de 17 de março de 2020 , $\mathrm{n}^{\circ} 345$, de 19 de março de 2020, e n ${ }^{\circ}$ 473, de 12 de maio de 2020. https://www.in.gov.br/en/web/dou/-/portaria-n-544-de-16-de-junho-de-2020-261924872

Brasil, (2020b). Ministério da Educação. Parecer CNE/CP No: 5/2020. Reorganização do Calendário Escolar e da possibilidade de cômputo de atividades não presenciais para fins de cumprimento da carga horária mínima anual, em razão da Pandemia da COVID-19. Brasília: Conselho Nacional de Educação, http://portal.mec.gov.br/index.php?option=com_docman\&view=download\&alias=14511-pcp005-20\&category_slud=marco-2020-pdf\&Itemid=30192

Cunha, L. F. F. da., Silva, A. de. S. \& Silva, A. P. da. (2020). O ensino remoto no Brasil em tempos de pandemia: diálogos acerca da qualidade e do direito e acesso à educação. Revista Com censo \#22, volume 7 n 3.

Fazenda, I. (2010). Pedagogia interdisciplinar: fundamentos teórico-metodológicos. Vozes.

Frizon, V., Lazzari, M. D. B., Schwabenland, F. P., \& Tibolla, F. R. C. (2015). A formação de professores e as tecnologias digitais. In Anais do XII Congresso Nacional de Educação-EDUCERE.

Japiassu, H. (1976). Interdisciplinaridade e patologia do saber. Imago.

Joye, C. R., Moreira, M. M., \& Rocha, S. S. D. (2020). Educação a Distância ou Atividade Educacional Remota Emergencial: em busca do elo perdido da educação escolar em tempos de COVID-19. Research, Society and Development, 9(7), 521974299.

Lima, L. da S., Rodrigues, G. A., Silva, M. C. S. B, Silva, R. M. \& Machado, L. M. (2020). Aprendizagem significativa - o processo ensino-aprendizagem no ensino remoto. Anais do xxv Seminário Internacional de Educação. 5(1).

Magalhães Jr. A, G \& Cavaignac, M. D. (2018). formação de professores: limites e desafios na educação superior. Cadernos de Pesquisa. 48(169),.902-920. https://www.scielo.br/j/cp/a/z6WWPsn78QWRNT7MPVRMg8p/?format=pdf\&lang=pt.

Morin, E. (2005). Ciência com consciência. (9a ed.), Bertrand Brasil, 350p.

Paz, M. S. O. de., Almeida, N. R. de., Araújo, J. P. de. \& Ramos, A. M. (2021). Envolvimento dos discentes nas atividades escolares em tempos de pandemia do COVID-19: Ações desenvolvidas pelo o IFPA - Campus Paragominas. Research, Society and Development, 10(3). http://dx.doi.org/10.33448/rsdv10i3.13470

Pereira, A.S., Shitsuka, D. M., Parreira, F. J. \& Shitsuka, R. (2018). Metodologia da pesquisa científica. UFSM.

Pinho, M. J. de, Medeiros, T. M. de S. \& Ribeiro, J. S. C. (2018). Complexidade e Transdisciplinaridade: novos caminhos para a educação do século XX. Revista Humanidades e Inovação. 5(3).

Ribeiro, V. M., Bonamino, A. \& Carvalho, C. P. Equidade e Desigualdade Escolar em um Recorte da Produção Acadêmica da sociologia da Educação sobre Políticas Educacionais no Brasil (2006- 2017). Jornal de Políticas Educacionais. 13(9).

Silva, A.V. V. da, Santos, H. dos R. \& Paula, L.H. de. (2021). Os desafios enfrentados no processo de ensino e aprendizagem em tempos de pandemia nos cursos de graduação. https://editorarealize.com.br/editora/anais/conedu/2020/TRABALHO_EV140_MD1_SA19_ID4434_14092020210502.pdf

UNESCO. (2020). Organização das Nações Unidas para a Educação, a Ciência e a Cultura. https://pt.unesco.org/covid19/educationresponse

Valente, G. S. C., Moraes, E. B. de.,m Sanchez, M. C. O., Souza, D. F. de. \& Pacheco, M. C. M. D. (2020). O ensino remoto frente às exigências do contexto de pandemia: Reflexões sobre a prática docente. Research, Society and Development, 9(9). http://dx.doi.org/10.33448/rsd-v9i9.8153

Vieira, K. V. M. \& Sousa, R. P. (2016). Objeto de aprendizagem empregado como recurso multimídia na microbiologia. In: Sousa, R. P et al. Teorias e práticas em tecnologias educacionais. Campina Grande: Eduepb. http://books.scielo.org/id/fp86k/pdf/sousa-9788578793265.pdf 